\title{
Implementation of the Peer-Led Team-Learning Instructional Model as a Stopgap Measure Improves Student Achievement for Students Opting Out of Laboratory
}

\author{
Julia J. Snyder, B. Elijah Carter, and Jason R. Wiles \\ Department of Biology and Department of Science Teaching, Syracuse University, Syracuse, NY 13244
}

Submitted August 26, 2013; Revised September 6, 2014; Accepted October 12, 2014

Monitoring Editor: Clarissa Dirks

In entry-level university courses in science, technology, engineering, and mathematics fields, students participating in associated laboratory sessions generally do better than those who have no related lab classes. This is a problem when, for various reasons, not enough lab sections can be offered for students and/or when students opt out of optional available lab courses. Faced with such a situation, this study evaluated the efficacy of the peer-led team-learning (PLTL) instructional model as a potential method for narrowing the achievement gap among undergraduate students electing not to enroll in an optional laboratory component of an introductory biology course. In peer-led workshops, small groups of students participated in solving problems and other activities that encouraged active learning. Students led by peer leaders attained significantly higher exam and final course grades in introductory biology than comparable students not participating in PLTL. Among the introductory biology students who opted not to enroll in the optional lab course, those who participated in PLTL averaged more than a letter grade higher than those who did not. This difference was statistically significant, and the PLTL workshops almost entirely closed the achievement gap in lecture exam and final grades for students who did not take the lab.

\section{CONTEXT}

In 2011, the Biology Department at Syracuse University instituted a revised curriculum for majors in the life sciences that, commendably, added more lab-based courses to the core requirements for students at the sophomore and junior levels and ensured a greater breadth of coverage in biology for the major overall. The new curriculum includes many improvements for biology majors, but there were unavoidable consequences for the introductory-level courses, primarily for the second-semester course in the general biology sequence. Historically, the course had included a required laboratory

CBE Life Sci Educ March 2, 2015 14:ar2

DOI:10.1187/cbe.13-08-0168

Address correspondence to: Julia J. Snyder (jjseymou@syr.edu).

(c) 2015 J. J. Snyder et al. CBE-Life Sciences Education (c) 2015 The American Society for Cell Biology. This article is distributed by The American Society for Cell Biology under license from the author(s). It is available to the public under an Attribution-Noncommercial-Share Alike 3.0 Unported Creative Commons License (http:// creativecommons.org/licenses/by-nc-sa/3.0).

"ASCB®" and "The American Society for Cell Biology ${ }^{\circledR}$ " are registered trademarks of The American Society for Cell Biology. component, but because the revised curriculum for biology majors required more graduate teaching assistants to staff the new upper-division lab courses and because many nonscience programs on campus require only one semester of science with a lab, the department decided to make the lab component for the second introductory course optional.

We were concerned for those students who would opt out of the lab, as we expected their achievement in the course to diminish without the weekly labs to provide hands-on, inquiry-based interaction with the material in an experiential and social environment. As we considered potential stopgap measures for this population, whatever we decided to implement had to fit within very specific budgetary and personnel constraints. Among the options we considered, peer-led team learning (PLTL) appeared to be the most evidence-based solution, but we could find no research related to its efficacy as a potential intervention for students who had chosen not to enroll in an optional lab component of an introductory biology course. Hence, as we were confident in its potential, we took it as natural opportunity to experiment, and we communicate here the results of our institutional review board-approved study with consent of $100 \%$ of the participants. 


\section{PRIOR RESEARCH ON PLTL AND ITS BENEFITS FOR STUDENTS}

PLTL is an instructional approach that provides an environment for students to engage in intellectual discussions and work in problem-solving teams under the guidance of a peer leader (Woodward et al., 1993). Like many cooperative-learning strategies, the PLTL model encourages students to actively engage in their own learning. Differing from traditional cooperative-learning strategies, however, this model provides some guidance to the students in a setting outside lecture and without direct instructor intervention (Cracolice and Deming, 2001).

The PLTL model involves teams of six to eight students, often referred to as the workshop, each with a peer leader who has recently and successfully completed the same course in which the students are enrolled. Prior success in the course, as a qualification for peer leaders, is generally defined as having earned a grade of " $\mathrm{A}$ " or " $\mathrm{B}$ " in the course. In addition, peer leaders should demonstrate good communication skills and leadership potential. The peer leaders facilitate group work among the team of students and are not responsible for providing answers to any of the problems. Because they are usually neither content experts nor experienced facilitators, peer leaders take part in a leader-training program in which the course instructor and an education specialist prepare the leaders to guide student-student interactions (Tien et al., 2004).

Since the introduction of the model into introductory chemistry courses, the PLTL approach has been implemented in many undergraduate science courses, and its effectiveness has been documented in regard to the academic benefits to students participating in the workshops.

Studies have shown improvements in students' grade performance (Gafney, 2001; Alger and Bahi, 2004; Wamser, 2006) and conceptual reasoning skills (Peteroy-Kelly, 2007). Additional studies indicate positive effects on student retention, with a decreased percentage of PLTL students who fail or withdraw from a course relative to non-PLTL students (Tien et al., 2002; Wamser, 2006; Stewart et al., 2007; Hockings et al., 2008).

The previous studies demonstrate that positive effects of PLTL on grade performance and student retention have been well established in introductory science lecture courses. McCreary et al. (2006) also demonstrated the positive effect of PLTL on student performance in a general chemistry lab. While these findings from a laboratory course mimic those from lecture settings, it is difficult to determine which aspects of the PLTL model are responsible for improvements in student performance, simply because the labs were carried out with an inquiry-based approach.

Of those studies that have examined the effects of PLTL, very few were implemented in introductory biology courses, and whether or not the PLTL model may be a good stopgap for students opting not to take the laboratory portion of a course has yet to be explored.

On the basis of the prior success of the PLTL model, we hypothesized that it would lead to increased achievement for all of our students who participated in the experience. However, we were most interested in the population of students who chose not to enroll in the optional lab, and we sought to examine the underresearched question of the efficacy of the PLTL model as a stopgap for these students.

\section{IMPLEMENTATION OF THE PLTL PROGRAM}

In the implementation of the PLTL component of our course, we adhered very strictly to the workshop model of PLTL described by Gosser (2001). We used a learning specialist (at the time, a PhD candidate with an interest in PLTL) who worked with the course instructor and provided training for the peer leaders. We recruited peer leaders by contacting students who had been successful in the course in recent years and inviting them to an informational meeting regarding potential service as a peer leader. During the information and recruitment meeting, which 75 interested students attended, potential peer mentors were asked to provide their schedule of availability during the week. After reviewing their availabilities, 37 students had schedules amenable to participation as peer leaders and agreed to serve in this capacity.

The newly designated peer leaders enrolled in a onecredit course that met once a week for training and organizational purposes, and they were asked to provide three 1-h time blocks for which they were available to run a workshop session during the week. After we received all 37 students' availabilities, each peer leader was assigned one 1-h time during the week to run a PLTL workshop. Between six and 10 PLTL workshops were scheduled each day, Monday through Friday, during the week.

The introductory biology course is very large (487 students enrolled during this study), and even with 37 PLTL sections of eight students each, we would only have been able to accommodate about half of the student population. So, participation in PLTL was optional. The schedule of PLTL workshop times was then posted online, and students in the introductory course signed up voluntarily to participate in the PLTL workshops. To minimize enrollment in each workshop based on prior student-leader friendships and student-student friendships and to minimize discrimination, peer leaders' names were not provided with the available workshop times nor were the students enrolling able to see the names of the other students who had already enrolled in each workshop. Each workshop was capped at eight students. Once the session was full, the session time would no longer appear available on the enrollment website. Although many more students signed up for the sessions than attended them, 136 students regularly participated in the voluntary PLTL workshops. Nine sessions constituted $75 \%$ participation. Students who attended fewer than nine sessions, of which there were few, were not included in the analyses, as they tended to attend only one or two sessions and/or dropped the course at a point at which we could not accurately assess their achievement other than to categorize them as having withdrawn.

We were initially concerned that self-selection would be an issue, since participation in the PLTL workshops and the lab course was voluntary. It seemed reasonable to expect that perhaps only high-achieving students would elect to enroll in the PLTL sessions or that a particular group of students might opt out of the labs. However, as this was the second course in a sequence wherein the lab was required for the first course, we examined the populations who opted out of the lab or who did not participate in PLTL against those who did enroll in these components according to their achievement in the first-semester course. There were no statistical differences between the grades in the first-semester course of 
the populations of students who did or did not enroll in the lab or PLTL for the second-semester course. When comparing across the four different groups of students (non-PLTL and non-lab, PLTL only, lab only, and PLTL with lab), we found that students who enrolled in the lab but did not participate in PLTL had achieved slightly but statistically significant higher marks in the previous semester. However, there were no statistical differences in prior achievement between other groups, including, most importantly for our study, between those who opted out of lab whether they participated in PLTL or not. These results were confirmed using analysis of variance (ANOVA) with Tukey honest significant difference (HSD).

The peer leaders met with a learning specialist for one 55-min class each week for 13 wk to discuss teaching and learning theory and how to apply it conceptually, debrief on previous weeks' sessions, and practice problem-solving strategies by collaboratively working on instructor-generated content problems. (See the Supplemental Material for sample problems.)

During the first training session, the learning specialist discussed the PLTL instructional model. Students were then asked to discuss what they believed the role of the peer leader was in the PLTL workshops. Following the group discussion, the first-day workshop agenda was given to the peer leaders. Peer leaders were also provided with a PLTL leader handbook (Roth et al., 2001) that included many assigned readings on learning theory and group dynamics.

At the start of each class succeeding the first, the learning specialist would either do a short activity related to the weekly reading assignment or ask whether there were any questions about the assigned readings. Peer leaders were then able to debrief on the previous weeks' sessions. During the debriefing time, peer leaders would share personal experiences with the other leaders, as well as the learning specialist. They would both offer and receive suggestions on how to handle various issues that arose during their PLTL workshops.

After the debriefing time, the learning specialist passed out the problem set for the week. Problem sets were developed by the learning specialist in consultation with the course instructor based on the weekly content of the introductory course. Weekly topics were of the typical variety found in postsecondary general biology courses using the most widely adopted textbooks (we use Campbell Biology). Topics were tightly aligned across lecture, lab, and PLTL sessions each week, as were content-learning objectives (as opposed to operational objectives specific to laboratory techniques). Each PLTL problem set had several activities for the workshop students to engage in. The learning specialist modeled the problem-solving methods each week by having the peer leaders collaborate in small groups on the problem-solving activities much like their students should. While answers were generally not provided to the problem-set activities, peer leaders were able to ask for clarification or helpful hints on any of the activities.

After the training session each week, the peer leaders facilitated a 1-h PLTL session without the presence of the instructor or learning specialist. Leaders offered guidance and support to their own students through the thought processes of solving the same problems they themselves worked on in their class with the learning specialist and other leaders.

\section{METHODS OF ANALYSIS}

Variables were tested for normality and found to be suitable for parametric analysis, which we report here. However, we also carried out nonparametric analysis due to the small sample size of our "PLTL-only" group, and found congruent results. For clarity, we will only report parametric statistics.

Independent $t$ tests were conducted to compare the achievement of the students as measured by their grades in the introductory biology course. Chi-square analysis was performed to determine any difference between the PLTL and non-PLTL groups.

Further comparisons between groups of students in the introductory biology course were analyzed through a one-way ANOVA. Historically, the course was offered for four credits and included the lab. With new curriculum changes in the biology department, the lab is no longer a required component. Students can take the one-credit biology lab course in addition to the three-credit lecture-based course, or they can choose to take only the lecture without the lab. Analyses were done to compare students not enrolled in either PLTL or the lab, students enrolled only in PLTL, students enrolled only in lab, and students enrolled in both PLTL and lab.

\section{FINDINGS: INFLUENCE OF PLTL ON STUDENT ACHIEVEMENT}

Grade performance analyses were performed for students who attended nine or more PLTL workshop sessions throughout the semester. Grade performance of the students in the PLTL workshops was analyzed using final exam scores in the Biology 123 course, final course grades in the Biology 123 course, and the percent of students receiving an "A," "B," or " $\mathrm{C}$ " grade (\%ABC) and a " $\mathrm{D}$ " or " $\mathrm{F}$ " grade $(\% \mathrm{DF})$ in the Biology 123 course. The final course grades were translated such that a grade of " $\mathrm{A}$ " corresponded to 89.5-100, “ $\mathrm{B}$ " corresponded to 79.5-89.49, " $\mathrm{C}$ " corresponded to $67.5-79.49$, " $\mathrm{D}$ " corresponded to $59.4-67.49$, and " $\mathrm{F}$ " corresponded to $<59.4$.

The mean final exam score of non-lab/PLTL students $(n=$ 26) was $77.92(\mathrm{SD}=10.35)$, while the mean final exam score of non-lab/non-PLTL students $(n=78)$ was $66.26(\mathrm{SD}=26.08)$. While the final exam scores ranged from a low grade of " $\mathrm{F}$ " to a high grade of "A," both groups' mean scores corresponded to a grade of "C." An independent $t$ test was conducted to compare the final exam scores of the non-lab/PLTL and non$\mathrm{lab} /$ non-PLTL students, and the mean performance of the non-lab/PLTL students was significantly higher than that of the non-lab/non-PLTL students $(t=-3.256, p=0.0020){ }^{1}$

\footnotetext{
${ }^{1}$ The grade averages reported here do not include those of students who withdrew from the course. Therefore, the average grades may appear somewhat high, and failure rates reported later may appear artificially low. Other studies have grouped students who withdrew together with those who have earned " $\mathrm{D}$ "s or " $\mathrm{F}$ "s, however, even high-achieving students withdraw for strategic purposes (e.g., perceptions of how a " $\mathrm{B}$ " or " $\mathrm{C}$ " might influence their grade point averages or admission to medical school) unrelated to "success" in the course as traditionally defined. Also, because only those students who attended a minimum of nine PLTL sessions were considered to have adequately participated, those who withdrew from the course before the 10th week of the semester could not be included in the analyses.
} 


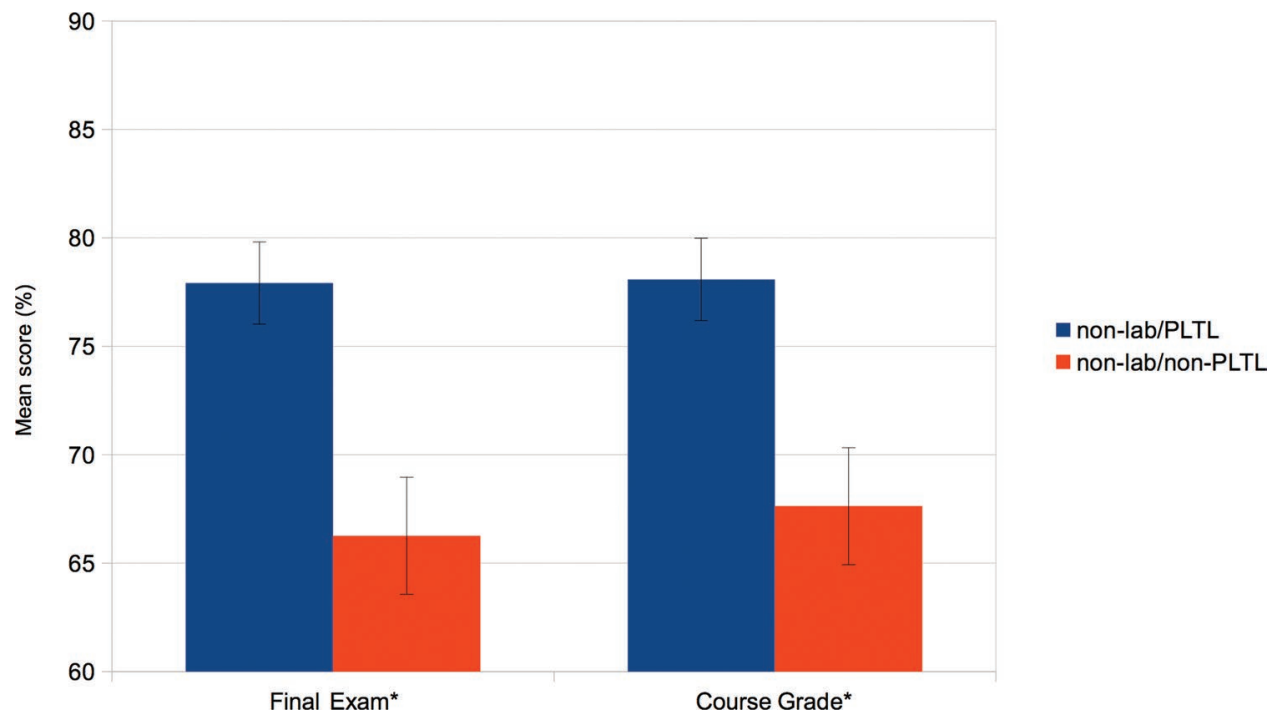

Figure 1. Mean score of final exam and final course grade of Biology 123 students (non-lab/PLTL $[n=26]$ vs. non-lab/non-PLTL $[n=78]$ ), during the Spring 2011 semester. Error bars indicate 95\% confidence intervals. ${ }^{*}$, significant at $p<0.05$.

Non-lab/PLTL students also earned significantly higher final course grades compared with non-lab/non-PLTL students $(t=-3.531, p=0.001)$. Of the 383 students with final course grades, non-lab/PLTL students earned an average grade of 78.09 (SD = 8.63), whereas non-lab/non-PLTL students earned an average grade of $67.63(\mathrm{SD}=21.44)$. While the final course grades revealed a wide range of scores spanning from a low of " $\mathrm{F}$ " to a high of " $\mathrm{A}$ " for both groups, the final course grades obtained by both groups corresponded to a "C." The mean final exam scores and final course grades of non-lab/PLTL and non-lab/non-PLTL groups are compared in Figure 1.

Chi-square analysis of final course grade percentages returned a significant difference for grade performance when comparing non-lab/PLTL students with non-lab/non-PLTL students $\left(\chi^{2}=6.516, p<0.02\right)$. Greater than $92 \%$ of the nonlab/PLTL students $(n=26)$ received an "A," "B," or " $\mathrm{C}$ " and less than $8 \%$ received a " $\mathrm{D}$ " or " $\mathrm{F}$ " compared with $\sim 67 \%$ of non-lab/non-PLTL students $(n=78)$ who received an "A," "B," or "C" and $33 \%$ who received a " $\mathrm{D}$ " or " $\mathrm{F}$ " (Table 1 ).

Table 1. Percentage of final course grades of Biology 123 students

\begin{tabular}{lcc}
\hline Grade percentage & $\begin{array}{c}\text { Non-lab/PLTL } \\
(n=26)\end{array}$ & $\begin{array}{c}\text { Non-lab/non-PLTL } \\
(n=78)\end{array}$ \\
\hline$\% \mathrm{~A}$ & 11.5 & 3.9 \\
$\% \mathrm{~B}$ & 30.8 & 25.6 \\
$\% \mathrm{C}$ & 50.0 & 37.2 \\
$\% \mathrm{D}$ & 3.9 & 15.4 \\
$\% \mathrm{~F}$ & 3.9 & 18.0 \\
$\% \mathrm{ABC}, \% \mathrm{DF}$ & $92.3, * 7.7^{*}$ & $66.7, * 33.3^{*}$ \\
\hline
\end{tabular}

*Significant at $p<0.05$, PLTL vs. non-PLTL.

Note: Grade percentage was calculated by summing all students with each grade and dividing by the total number of students enrolled in each group.
Further analysis of final course grade percentages was conducted to compare a group of non-PLTL/non-lab students, a group of PLTL-only students, a group of lab-only students, and a group of PLTL/lab students. A one-way ANOVA revealed that there were significant differences between groups $(F=17.893, p<0.001)$. A follow-up Tukey HSD analysis revealed that PLTL-only students, lab-only students, and students enrolled in both PLTL and lab all had significantly higher final grade percentages than the nonPLTL/non-lab students.

When PLTL-only students were compared with lab-only students, there was no significant difference found between the groups. Mean final course grades by group are reported in Table 2. The average final grade percentage for PLTL-only students was 78.09 compared with 79.50 for the lab-only students. While the students who were enrolled in both PLTL and lab earned the highest final grade percentages, there was no significant difference found between those students and students enrolled in PLTL only or lab only. The average final grade percentage for the students enrolled in both PLTL and lab was 80.64 compared with 78.09 and 79.50 for students enrolled in PLTL only or lab only, respectively. Comparisons of mean final course grades are shown in Figure 2.

Table 2. Mean scores of Biology 123 students

\begin{tabular}{lccc}
\hline \multicolumn{1}{c}{ Group } & Sample size & Final exam $^{\mathrm{a}}$ & Final course grade $^{\mathrm{a}}$ \\
\hline $\begin{array}{l}\text { Non-PLTL } \\
\quad \text { and non-lab }\end{array}$ & 78 & $66.26( \pm 2.95)$ & $67.63( \pm 2.43)$ \\
PLTL only & 26 & $77.92( \pm 2.03)$ & $78.09( \pm 1.69)$ \\
Lab only & 169 & $78.87( \pm 1.05)$ & $79.50( \pm 0.85)$ \\
PLTL and lab & 110 & $79.72( \pm 0.89)$ & $80.64( \pm 0.82)$ \\
\hline
\end{tabular}

aSEMs are in parentheses. 
Final Grade Performance of Student Groups in Biology 123

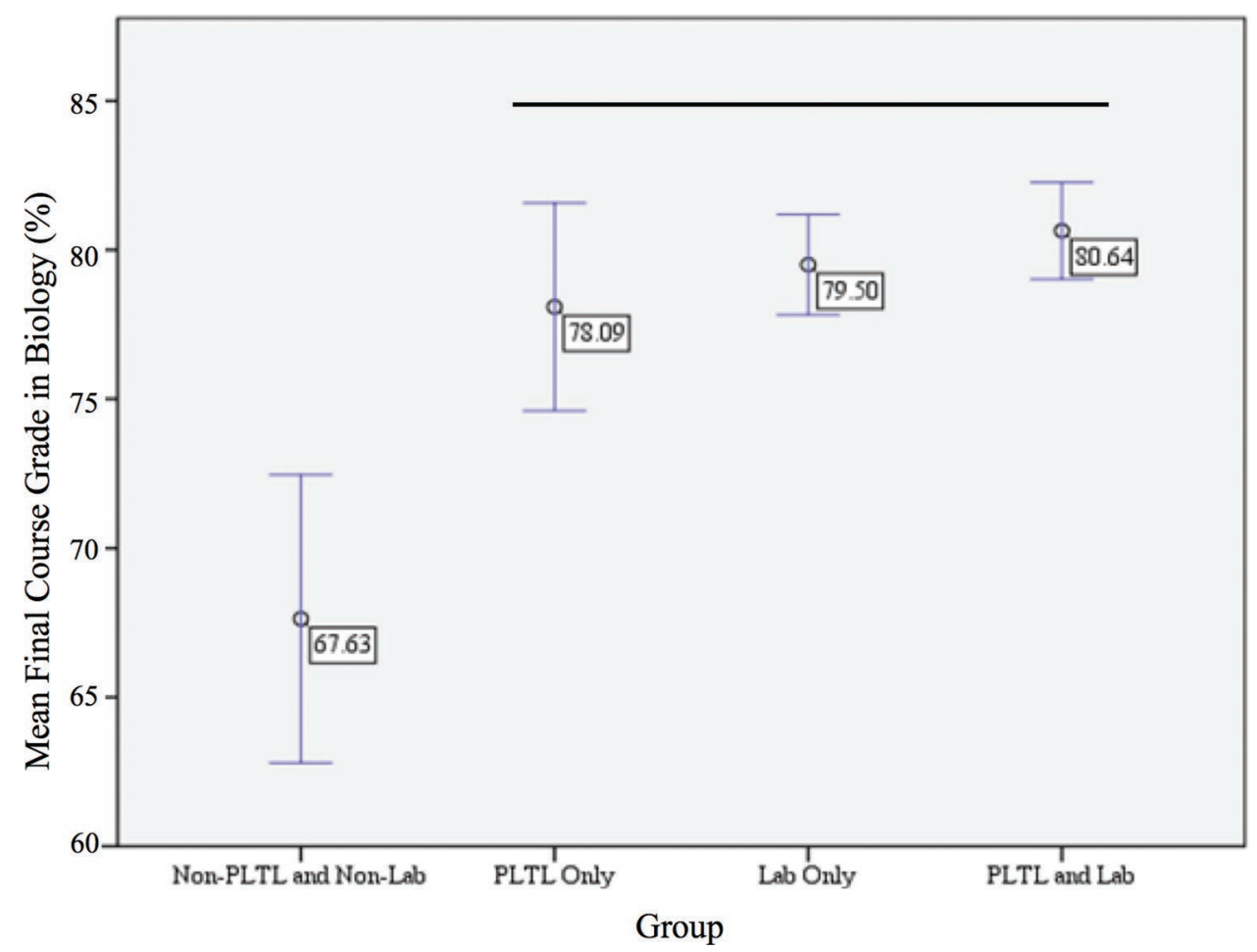

Figure 2. Mean final course grade of Biology 123 students during the Spring 2011 semester. Line overbars indicate groups that were not significantly different (Tukey's HSD, $p<0.05$ ). Error bars indicate 95\% confidence intervals; non-PLTL and non-lab: $n=78$; PLTL only: $n=26$; lab only: $n=169$; and PLTL and lab: $n=110$.

\section{CONCLUSION}

It is evident that PLTL had a significant influence on student achievement in our introductory biology course. These results are consistent with prior research and with our hypothesis that PLTL had potential as a stopgap measure for students who elected not to enroll in the optional laboratory courses. We expected that students who did not enroll in the lab would not achieve at the level of students who did, although there were no differences in their achievement during the previous course in which the lab was required. And indeed, the course grades for non-lab students were significantly lower, unless they participated in PLTL workshops. While non-lab students were not engaged in a hands-on, inquiry-based lab experience, PLTL workshops provided an active-learning environment for students to construct their own understanding of scientific concepts within a social context. Engaging in PLTL workshops almost entirely closed the achievement gap for students who did not take the lab.

However, we wish to be clear that we are not advocating PLTL workshops as a replacement for a true laboratory experience. While the regular exposure to concept-based problem solving in a social context may be effective in helping students to construct a more solid understanding of the subject matter, it is no substitute for laboratory-based inquiry. It is interesting that engaging in the laboratory, which does incorporate team learning and problem solving, provided similar but not significantly additive returns compared with PLTL activities in terms of lecture exam performance; however, laboratory work surely has additional benefits. The most obvious difference is that PLTL workshops on their own do not allow students to obtain familiarity with lab equipment or basic skills fundamental to participation in upper-division science courses or research experiences. The lack of an opportunity to attain these skills remains an extension of the achievement gap that may well be impossible to mitigate without a laboratory course component. However, for those students who do not or cannot enroll in a laboratory course for various reasons, PLTL can provide a means for diminishing the achievement gap between students who do and do not take the lab.

\section{ACKNOWLEDGMENTS}

The authors thank Beverley Werner for her assistance in the coordination of participant activities and technical skill in data organization. We also thank the Biology Department at Syracuse University for its support throughout this project. The development of this article was funded in part by a grant from the National Science FoundationEAGER: Enhancing Recruitment and Retention of Underrepresented Populations through PLTL (NSF award 1352740). Any opinions, findings, and conclusions or recommendations expressed in this material are those of the author(s) and do not necessarily reflect the views of the NSF.

\section{REFERENCES}

Alger TD, Bahi S (2004). An experiment in improving scores on ACS course-specific examinations at Southern Utah University. Progressions: The PLTL Project Newsletter 5, 7-10. 
Cracolice MS, Deming JC (2001). Peer-led team learning. Sci Teach $68,20-24$.

Gafney L (2001). Evaluating students' performance. Progressions: The PLTL Project Newsletter 2, 3-4.

Gosser D (2001). The peer-led team learning workshop model. In: Peer- Led Team Learning: A Guidebook, ed. D Gosser, M Cracolice, J Kampmeier, V Roth, V Strozak, and P Varma-Nelson, Upper Saddle River, NJ: Prentice Hall, 1-12.

Hockings SC, DeAngelis KJ, Frey RF (2008). Peer-led team learning in general chemistry: implementation and evaluation. J Chem Educ 85, 990-996.

McCreary CL, Golde MF, Koeske RJ (2006). Peer instruction in the general chemistry laboratory: assessment of student learning. J Chem Educ 83, 804-810.

Peteroy-Kelly M (2007). A discussion group program enhances the conceptual reasoning skills of students enrolled in a large lecture-format introductory biology course. J Microbiol Biol Educ 8, 13-21.
Roth V, Goldstein E, Marcus G (2001). Peer-Led Team Learning: A Handbook for Team Leaders, Upper Saddle River, NJ: Prentice Hall.

Stewart BN, Amar FG, Bruce MRM (2007). Challenges and rewards of offering peer led team learning (PLTL) in a large general chemistry course. Aus J Educ Chem 67, 31-36.

Tien LT, Roth V, Kampmeier JA (2002). Implementation of a peer-led team learning instructional approach in an undergraduate organic chemistry course. J Res Sci Teach 39, 606-632.

Tien LT, Roth V, Kampmeier JA (2004). A course to prepare peer leaders to implement a student-assisted learning method. J Chem Educ 81, 1313-1321.

Wamser CC (2006). Peer-led team learning in organic chemistry: effects on student performance, success, and persistence in the course. J Chem Educ 83, 1562-1566.

Woodward A, Gosser DK, Weiner M (1993). Problem solving workshops in general chemistry. J Chem Educ 70, 651-652. 